\title{
Climate Change Adaptation and Flood Management in Metro Vancouver Regional Area: Can an Exercise in Herding Cats be Successful?
}

\author{
Lilia Yumagulova"1, Ilan Vertinsky² \\ ${ }^{1}$ School of Community and Regional Planning, University of British Columbia, 293-2357 Main Mall, \\ Vancouver, Canada \\ e-mail: lily.yumagulova@gmail.com \\ ${ }^{2}$ The Sauder School of Business, University of British Columbia, 2053 Main Mall, Vancouver, Canada \\ e-mail: ilan.vertinsky@ubc.ca
}

Cite as: Yumagulova, L., Vertinsky, I., Climate Change Adaptation and Flood Management in Metro Vancouver Regional Area: Can an Exercise in Herding Cats be Successful?, J. sustain. dev. energy water environ. syst., 5(2), pp 273-288, 2017, DOI: http://dx.doi.org/10.13044/j.sdewes.d5.0149

\begin{abstract}
Climate change poses novel challenges for cities, threatening long-term sustainability objectives and necessitating investments in resilience. Climate change exacerbates the challenge of identifying the range of impacts of natural hazards in terms of scale and frequency. This study focuses on climate change adaptation responses with regard to flood management in the Metro Vancouver regional area, which is the last large non-amalgamated region in Canada. It is comprised of 24 local authorities and a regional government with delegated and distributed authority for flood management and other responsibilities. The area is subject to river flooding, intense rain storms and an increasing rate of sea level rise. The study identifies mechanisms by which the municipalities make sense of the existing hazards as well as how they design and invest into responses for future risks under conditions of uncertainty. Given the geographic, demographic and socio-economic differences across municipalities in the region, the study found a diverse set of responses in planning regimes in regard to the long-term risks as well as the short-term political pressures that municipalities face. This resulted in a significant variability of planning policies and practices across the region, which could potentially reduce overall regional ability to adapt to change. The paper concludes with a discussion of measures that can be taken to strengthen the regional coordination process.
\end{abstract}

\section{KEYWORDS}

Climate change, Adaptation, Regional planning, Networks, Coordination.

\section{INTRODUCTION}

Climate change poses novel challenges for cities, threatening the status quo of urban planning and asset management systems, as well as placing an increasing burden on emergency preparedness and response systems. The changes in intensity and duration of extreme events increasingly overwhelm ageing infrastructure and disrupt the critical lifelines that serve cities. Climate change also challenges fundamental assumptions upon which urban infrastructures have been built. In water management sector, the assumption

\footnotetext{
${ }^{*}$ Corresponding author
} 
of 'stationarity' that historically facilitated management of supply, demand, and risk is becoming increasingly irrelevant [1], which means that projections based on past experiences should not be used for designing future water infrastructure systems. In the energy sector, Buceti [2] shows how an interdependent relationship between emissions and impacts of climate change (e.g. extreme weather events, drought, sea level rise) on supply capacity and shifts in energy demand varies from region to region [2].

Mitigation and adaptation are the two fundamental policy approaches for reducing the environmental, economic and social threats posed by climate change. While mitigation is aimed at proactive reduction of the amount of emissions released, adaptation deals with the consequences of inadequate mitigation efforts. Some experts have argued that, to date, much of the emphasis in planning for climate change has been focused on mitigation $[3,4]$ with policy inaction concentrated at the higher international and national scales. However, mitigation also makes economic sense at a local-regional scale. For example, urban planners in the province of Alberta, Canada have calculated that cost savings associated with increased development density and limited metropolitan sprawl could save USD 11 billion in capital costs over the next 60 years and USD 130 million in annual maintenance costs [5]. Effective mitigation planning can result in sustainability co-benefits but this requires establishment of regulatory framework, institutional framework and development of clear action plans for realizing the implementation of mitigation measures [6].

There is some evidence that adaptation has received much less attention by municipal decision makers and planners and is therefore a nascent policy field at the city level [7]. Yet a recent global survey [5] shows a significant amount of catch-up in adaptation planning: $75 \%$ of cities worldwide report that they are engaging in both adaptation and mitigation planning, with just under $24 \%$ focusing exclusively on mitigation. The United States is the one notable exception, with $58 \%$ of cities reporting that they engage with both adaptation and mitigation. The US also has the highest percentage of cities conducting mitigation planning only $(41 \%)$. Another trend that speaks to mainstreaming of climate change initiatives is integration of climate change planning into other local government plans (i.e. long range, land-use and sustainable development plans) rather than stand-alone documents. Globally, Canadian cities have made the most progress in this direction, while African and American cities report the lowest rates of integrating climate change into other municipal plans [5]. Few studies have explored the mechanisms behind this progress among Canadian cities. Furthermore, despite the increased importance of adaption planning at the local level, there is a lacuna of studies that situate the municipal mechanisms of adaptation planning within the regional-metropolitan level and multi-level governance. This article addresses this gap by focusing on the following questions: What mechanisms facilitate or hinder the development of regional adaptation planning at the metropolitan level? What is the role of senior governments in guiding this process? What is the role of external institutions in enabling regional collaboration? We answer these questions using a longitudinal in-depth Canadian case study of the Metro Vancouver region, British Columbia (BC), a partnership of 21 municipalities, one Electoral Area and one Treaty First Nation. The Metro Vancouver area is known internationally for progress on mitigation. In 2008, BC introduced North America's first economy-wide carbon pricing policy: a revenue-neutral tax on carbon pollution, which remains the continent's strongest carbon-pricing initiative today and has been recognized globally for the effectiveness of its design [8]. The study region is also home to the City of Vancouver, which aims to become the Greenest City of the world by 2020 .

Adaptation is a process rather than status which means that a case study approach is the most fitting methodology to address the procedural dimensions of adaptation planning across scales of governance. 
The paper first presents the theoretical framework underlying adaptation planning as a policy domain and secondly situates it within multi-level governance framework with an emphasis on a principle of subsidiarity. This is followed by background on the Metro Vancouver region and its planning system and policy context. The final sections present analyses and discussion of our field study, concluding with recommendations.

\section{THEORETICAL FRAMEWORK}

\section{Adaptation planning as an emerging policy field}

Adaptation planning emerged as a policy domain and branch of urban and regional planning in response to the urgent need for reducing the vulnerability of city functions and urban residents to the direct and indirect impacts of climate change. Some examples of these impacts include the increased incidents of extreme weather events, urban flooding, droughts and heat waves, as well as increasing risk of sea-level rise, storm surges and salt water intrusion in low-lying agricultural lands, among many others. There are many reasons that make adaptation planning a particularly challenging policy domain. In the following discussion we focus on three that are most pertinent to local level adaptation:

- Scientific uncertainty of local level data that requires investments today for potentially uncertain payoffs in the future;

- Political municipal short term cycles that can inhibit necessary long term action;

- The breadth of impacts that necessitates participation of a wide spectrum of actors, challenging the established patterns of operation.

Local scale is where the mitigation inaction rubber hits the adaptation road. It is the most directly accountable and locally informed level of governance, controlling building, development, land use, and providing basic services such as water, sewer and emergency protection. While the scientific consensus of the impacts of climate change at the global scale is uncertain, there is even greater uncertainty at the local-regional scale. Roberts [9], drawing on experience in Durban, South Africa, stresses that without developing a meaningful understanding of the science, climate change and its significance are unlikely to be effectively understood and acted upon at the local government level. The climatic uncertainties at the local level are compounded by uncertainties in the political sphere, by institutional and technological change, and by evolving societal values and economic fluctuations at the local and global scales [10]. Considering these pressing challenges and the limited resources that cities have, the long-term nature of planning for climate change often does not get enough attention or political will during short-lived office-terms, especially under condition of fiscal austerity. As Wagner and Zechhauser [11] suggest, "policy makers can and must try to overcome inherent psychological barriers and create pockets of certainty that link benefits of climate policy to local, immediate payoffs". Another major obstacle to the anticipatory approach is the "shared governance" implementation dilemma wherein the higher level of government has a strong stake in promoting a policy for avoiding development in hazardous lands, but lower governing bodies are unwilling partners [12,13]. Senior levels of government encourage local implementation to ensure a reduction of the financial burden (e.g. disaster aid) that they will have to shoulder in an event of disaster. However, local governments are concerned with more immediate and visible objectives such as housing, homelessness, crime, and other objectives that better fit short term political tenures. This results in a tendency to discount lower probability, high consequence events such as catastrophic flooding, especially as in a case of such an event, the senior government will have to distribute disaster aid due to political pressures. This dilemma is emphasized even more in a regional context where land use management programs for hazard mitigation cannot be effective without difficult-to-achieve cooperative intergovernmental coordination [14]. 
Thus, fragmented governance systems tend to discount cumulative effects of land-use changes [14]. In the context of climate change, this means that failure to plan and act regionally can significantly undermine long term adaptation options for regions as a whole. On the other hand, a study of 156 municipalities in the US suggests that regional planning entities can help overcome some of the adaptation planning barriers (e.g. the lack of local fiscal capacity and political support) by facilitating the exchange of information, pooling and channeling resources, and providing technical assistance to local planners [15].

Building supportive institutions that are capable of dealing with changing environmental risk across jurisdictional boundaries and are prepared to adopt new basic operating assumptions are some of the key challenges of adaptability. The broad scope of climate change impacts, ranging from affecting physical infrastructure (i.e. drainage systems) to health (heat waves and disease) to overwhelming services (emergency management), makes it difficult to assign a specific department the responsibility for adaptation. This means that adaptation is no longer under the purview of the environmental sector [16]. It calls for the participation of a broad range of stakeholders to address this complex multi-scalar problem given the procedural, substantive and legitimacy benefits [17]. As a result, local governmental action on climate change, once a narrowly environmental concern, is increasingly mainstreamed in municipal bureaucracy [5]. The downstream/upstream and cascading effects of urban vulnerabilities such as flooding or power outages also make it clear that municipal jurisdictional boundaries are limiting an effective adaptation action, calling for broader regional level cooperation, by working across the silos and adopting an ethos of shared responsibility across multiple scales of governance.

\section{Regional adaptation planning and multi-scale governance}

Climate change poses significant governance challenges. While it is clear that mitigation and adaptation require a multi-level governance structure with cooperative actions at the different institutional scales [18] it not as clear what governance form can effectively address climate change adaption planning at a regional/metropolitan scale. For example, while the Southeast Florida Regional Climate Change Compact has been celebrated as one of the leading examples of regional-scale climate action in the U.S. and was highlighted by the President Obama as a "model not just for the country, but for the world" closer analysis shows that it lacks representation, decision making, learning and problem responsiveness [19].

Growing cities and their growing demographic, fiscal and environmental challenges and opportunities have resulted in a key question for urban regions world-wide: how to effectively match the existing and emerging problems with a system of government and/or governance that is capable of managing them [20]? Governance rather than government emerged in response to the growing complexity of governing in a globalizing and multilevel context. In particular, adaptive governance that supports "the evolution of new governance institutions capable of generating long-term, sustainable policy solutions to wicked problems through coordinated efforts involving previously independent systems of users, knowledge, authorities and organized interests" [21]. Regional planning varies significantly as a function of regional governance form. Regional planning can be defined as a process designed to regulate, manage and control potentially competing priorities of city-regions (i.e. land use, growth, environmental protection, or air quality) based on a collective vision for a specific geographic area. Metropolitan regional government takes two primary forms: amalgamated and non-amalgamated. The amalgamated form calls for the abolishment of prior existing cities and districts in favour of establishment of one general-purpose government for the 
entire metropolitan area [22]. The second form of government is a federative, two-tier structure, where a separate new overhead unity serves as a general purpose metropolitan government, providing regionally oriented system maintenance services such as water, sewers and public transport. In this model, existing towns and cities are retained and they continue to be responsible for delivering local lifestyle services [22].

Under the Canadian system, municipalities are seen as the 'creatures of the province' and the senior governments can annex and merge urban governments as they struggle with the challenges of metropolitan growth and demands for coordination, common standards, and economies of scale. While amalgamation offers some efficiency benefits, it also has some organizational costs. Civic governments become further removed from the people, and lose the flexibilities and efficiencies that smaller-scale delivery provides [23]. In an attempt to reduce management costs, increase efficiency of service and increase distributed fiscal fairness, the majority of Canadian regions have gone through waves of amalgamation and annexation since the 1950s [23]. Metro Vancouver is Canada's last, large non-amalgamated area which supports and celebrates the diversity and independence of its 24 members.

Given that the impacts of global climate change are local and contextual, the principle of subsidiarity becomes an important governance principle. It states that "public responsibilities should be exercised by those elected authorities, which are closest to the citizens" [24] and that government functions should be assigned to the lowest level of government that is capable of efficiently undertaking this function [25]. Subsidiarity is one of the key principles of the European Community legal framework [26]. Wilkins suggests that it is "a key principle in discussions about federalism that decision making should be devolved to the most local level possible; or, conversely, decision making should only be centralised where it is necessary to do so" [27].

\section{RESEARCH CONTEXT}

The Metro Vancouver region is located in $\mathrm{BC}$, the westernmost province of Canada. Nearly $55 \%$ (2.5 million) of the population of the province lives in the region which lies at the foothills of mountains, surrounded by ocean at the mouth of the Fraser River (Figure 1). This densely populated region is subject to frequent seismic activity, which puts it at the higher risk of catastrophic earthquake than other parts of Canada. It is also subject to intense rain storms, potentially catastrophic river flooding and an increasing rate of sea-level rise. Intensive development has altered the shoreline for industrial, commercial and residential use. Dikes, sea walls, piers, and other armouring has allowed building and structure placement down to sea level and below. The projected rise in sea-level and storm surge are beyond the capacity of these structures, which, by virtue of their design increase their vulnerability as they amplify wave energy and increase wave deflection [28]. The municipalities that lie at the foothills of the mountains also face numerous creek hazards, landslides and risk of dam breaches in certain locations. The municipalities that lie on the soft soils of the Fraser River delta and are bordered by the ocean are subject to ongoing subsidence, flooding from storm surge and liquefaction in the event of an earthquake. The risks of catastrophic loss from a major flood are highest in the region because it has a large population and important regional, provincial and national infrastructure situated in the floodplains. Approximately 300,000 people are protected by the dikes and an estimated USD 50 billion of infrastructure and property is at risk [29].

In addition to the animated natural hazards profile, the historical positioning of now aging infrastructure puts the airport, ports, highways, bridges, ferry terminals, oil and gas pipelines, as well as hydro-electricity, wastewater and water systems, and 
telecommunications networks at risk. A large magnitude flood is likely to affect a significant portion of the region's population, directly or indirectly, and will disrupt local, regional, provincial and national economic activity [30]. The Greater Vancouver regional district's jurisdictional area, hereafter referred to as 'the region', is comprised of 24 local authorities (22 municipalities, one First Nations and one unincorporated area) and "Metro Vancouver", the political body and service provider that oversees the 24 local authorities with delegated and distributed authority for flood management, among other responsibilities. The member municipalities range in demographics (from Canada's most stable to fastest growing municipalities), size variance (from villages of 650 to the City of Vancouver at 650,000 residents), cultural diversity, economies, and geographical and historical contexts. These factors, combined with drivers of change and risk, make this region a rich case study for furthering the understanding the dynamics behind regional adaptation planning.

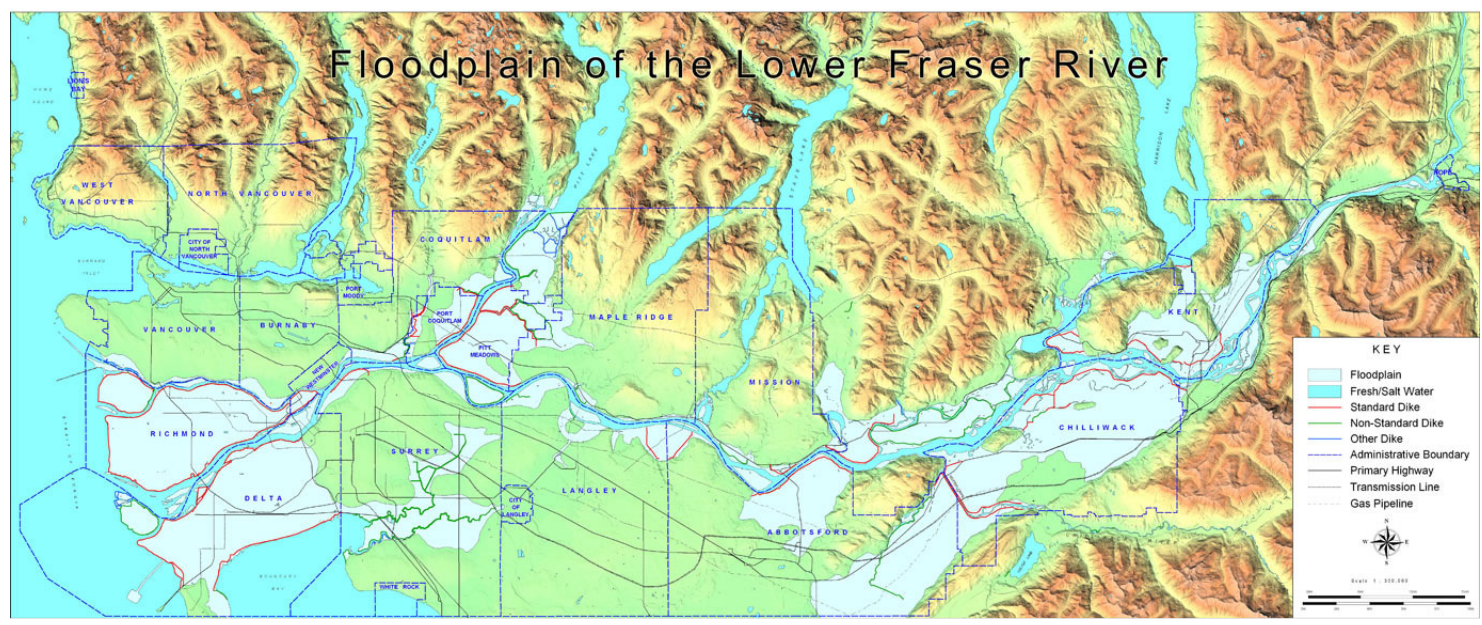

Figure 1. Floodplain of the Lower Fraser River [30] (used with permission)

\section{METHODS}

This study uses data collected over two and a half years and draws on interviews conducted at the municipal, regional and provincial levels $(N=60)$ and a targeted regional survey of municipal practitioners (engineers, emergency managers and planners) involved in flood management and adaptation planning $(N=33)$. As illustrated in other case studies, the semi-structured expert interview methods allow to effectively gather knowledge on the barriers and enablers of planning and development efforts $[19,31]$. The structured survey approach allows to triangulate qualitative and quantitative data. In addition to these primary data, secondary sources such as policy, strategic documents and plans were also analyzed.

The number of studies on adaptation planning has grown significantly in the past few years. For example, Aylett [5] conducted a global survey on mitigation and adaptation planning, while Shi, Chu, \& Debats [15] surveyed 156 municipalities across in the United States of America. Numerous qualitative case studies have been conducted: for example, in Italy and Finland [16] and Southeast Florida [19]. However, few studies have employed mixed methods approaches to explore regional adaptation planning nested within multilevel governance.

In accordance with the research ethics protocol for this study, the participants remain anonymous throughout the document, represented by a number in order of study participation (e.g. P1 for interviewees and SP1 for survey participants), unless otherwise specified. 


\section{FINDINGS AND DISCUSSION}

The findings are organized as follows. Firstly, the role of senior (provincial) government is discussed, which reveals the successes and limitations of centralized approaches to regulating adaptation and encouraging action. We then review two municipal mechanisms for framing and introducing climate change planning and regulating natural hazard risk. We find that municipalities are unlikely to self-regulate their land use risk through the most obvious mechanism, such as the Official Community Plan, the key land-use document that serves as blueprint for long term development. We also find that the municipalities are unlikely to address the planning incentives provided by the senior government unless there is a significant and direct cost to their inaction or significant benefits that cover the costs of action. In the absence of sufficient action at the local and provincial level, we turn to the discussion of the role of an important non-governmental organization, Fraser Basin Council, which builds institutional capacity to collectively plan for flood management in the region.

\section{Triggers of action: the role of senior government}

BC's flood management regime can be characterized as reactive (driven by crisis events, such as extensive flooding events of 1948, 1972), favouring of structural approaches (such as select river and sea dikes that often provide a false sense of security and increase development behind the dikes thus putting more property at risk), continuous cuts to programs, staff and funding at the higher levels of federal and provincial government, and increasing downloading of responsibilities to the municipal level [32].

The historical 1948 Fraser Valley flood levelled communities along the river and washed away agricultural land and initiated regional planning in the area [33]. However, hazard mitigation has not been a regional or provincial priority [34] and has seen a continuous reduction of federal and provincial responsibilities such as flood mapping programs, dike financing and provincial oversight of municipal land use and development.

The analysis of the more recent flood regime (2004-14 study period) shows that a major shift in policy occurred in 2003-04. Responsibilities were transferred to the local government for flood hazard area land use management, granting the authority to exercise a degree of discretion in developing their own policies for zoning, development permits, subdivision approvals, bylaws, and building permits through the statutory authority. Legislative changes to the Land Title Act and the Local Government Act in 2003 and 2004 removed the role of the Province for flood plain designation and approval, shifting this authority entirely to local governments which can now make decisions on where and how to develop without direct provincial oversight. This devolved responsibility could be seen as advantageous in the light of subsidiarity principle which calls for decisions to be made at the most local level possible [27] by elected officials that are closest to the citizenry [24].

Under the current regime, the Province is responsible for setting guidelines for municipalities, such as the Flood Hazard Area Land Use Management Guidelines published under the Environmental Management Act. These Guidelines were intended to assist local governments in identifying and designating flood hazard areas. However, the 2004 Guidelines were designed to address periodic flooding events (e.g. caused by spring floods of the Fraser river), and not permanent inundation due to sea level rise. Since 2001, the province has engaged in providing some guidance for sea level rise. This has included information about relative sea level rise along the BC coast [35], preliminary guidance on including this information in coastal dike design [36], guidance for professional on flood hazard and risk assessments in a changing climate [37], flood plain 
mapping guidelines [38] and adaptation processes guidance [39]. However, municipalities had limited experience to relate to this task and while they were provided with some guidance they were not provided with additional resources by the province as discussed below in a review of key policy drivers and municipal responses.

In 2011, the Province released proposed amendments to the 2004 guidelines that would reflect sea level rise. The guidelines recommended planning around a 0.5 -metre rise for developments with design lifespans up to the year 2050, and 1.0-metre of sea level rise up to the year 2100 [38]. The report highlighted that significant cross-government collaboration and education will be needed to deal with the effects of sea level rise on BC's coastal communities. Ironically, the proposed amendments were released without advance consultation with municipalities. The interview respondents suggested that the guidelines released did not carefully account for municipal implications of this guidance (e.g. land use, planning, zoning, and property tax impacts). The lack of consultation created a heightened sense of uncertainty despite the fact that the guidelines, in an unprecedented way, provided an affirmative 'policy' number of 1.0-metre sea level rise by 2100 that reduced scientific uncertainty. This created an active discussion in the region, through formal and informal channels. Subsequently, the local governments were invited to provide feedback on the proposed amendments. A number of concerns were raised, i.e. the possibility that each local government across the province would choose to address sea level rise differently, resulting in a context where building requirements, zoning, etc. would be different in each jurisdiction. Several have questioned if a standardized requirement, rather than a piecemeal approach through Local Government Act, would be more appropriate [40].

Another provincial document, the "Cost of Adaptation - Sea Dike and Alternative Strategies" study further significantly raised the profile of sea-level rise as a critical policy issue [41] and ignited an active collective discussion in the region. The study provided an estimated price tag of USD 9.47 billion for the adaptation measures for the selected 33 shoreline reaches to accommodate the provincially indicated 1.0-metre of sea-level rise in the coastal area of the region. The cost estimate provided intended to help to define the scale of the work ahead as a first step in developing a regional flood protection adaptation strategy. This has been a significant wake-up call for municipalities, as the previous way of doing business had to be seriously re-configured, but without adequate information, additional support from senior levels of government, and under conditions of overstretched municipal budgets. In the words of one of the survey respondents: "Whilst the province provides some guidance on SLR, the downloading of responsibility to research, fund, gather expertise and data and implement coastal flooding land use policies and regulations has created uncertainty, cost and staffing implications for our municipality" (SR12). The study also raised the prominence of the multi-hazard interface issue, putting some price tags on the seismic upgrades needed to prevent breaching in an event of an earthquake. As a result, while a number of municipalities have chosen to actively address sea level rise within municipal planning and to accept the Provincial guidelines, other groups chose to proceed as usual, at least for now, preferring not to invest their resources to protect themselves from specific low probability/high consequence hazards (such as an earthquake-related breach of the dike), as this would take away resources from other more immediate high-priority municipal objectives. Some municipalities decided to conduct their own in-depth studies before making any commitments. The diversity in municipal responses to climate change was not limited only to their responses to the Provincial guidelines but also to the mechanisms they used to address hazard management and the degree to which these mechanisms were deployed to address the threats of climate change. The next sections review two key mechanisms by which municipalities have been addressing natural hazard risk and climate change planning. 


\section{Municipal mechanisms for addressing climate change: Trusting cats to herd themselves?}

Municipalities have different mechanisms and tools by which they can address climate change, regulate their land use, and reduce the risk of natural hazards and floods in particular. Given the limited space in this paper we chose to address two key mechanisms:

- A visionary document that encapsulates long-term sustainability strategies for the municipality (e.g. Sustainability Charter or Environmental Plan);

- An Official Community Plan, a key guiding document for local development.

A large number of municipal staff and elected officials emphasized that it was mitigation planning that brought them to adaptation planning. Once municipalities made sense of climate change and the need for organizational action, adaptation planning was a logical extension. An elected municipal official from the city of Vancouver observed that "We have the Greenest City Action Plan so it made sense from our perspective that if we agree that climate change is happening and we need to try and mitigate it then we should also understand that its happening and there's a certain level no matter how we do at mitigating to this point where, we will have to respond to extreme weather events" (P41). Adaptation simply "made sense" and there was region-wide recognition that the municipal emissions reductions meant "nothing" globally (P29). However, there was also a recognition of a need to be prepared locally for the impacts, given how much the atmosphere has changed (P13, P41, P29). While some of the mitigation planning took began as early as 1995 for the City of Vancouver and took years to develop, the adaptation process was much quicker to catch up, with a full adaptation strategy being completed for 3 municipalities within 2-3 years. As one of the municipal environmental planners observed: "We have worked since 2007 on a corporate climate change initiative that focuses on mitigation... the environmental impacts of climate change got me into the whole mitigation thing so that's the core of the problem: if we mitigate our impacts then the environment will be less impacted. And then from there it was just like a rabbit hole of like "oh" and then there is this cool thing about adaptation..." (P13).

The key observable difference between the mitigation and adaptation processes was the level of public engagement: while the mitigation plan involved large scale public consultation and engagement, adaptation planning was seen as an internal objective. The municipalities had to make sense of the impacts, the vulnerabilities, and the options for addressing adaptation first, prior to engaging the public.

Within this process participants emphasized that a higher level vision document that enshrines the organizational values with regard to environmental objectives and programs was a very important policy support tool. It provided clarity for long term vision as well as any subsequent policy offshoots, such as sector specific plans. As one engineering staff member said: "It is easy to collaborate when you have the (Sustainability) Charter, when you get clear instructions... There's no uncertainty about what council's thoughts are on topics and to have them support whether it be the Sustainability Charter and its children, like the Community Energy and Emissions Plan and the Climate Action Adaptation Strategy. You know there's a lot of support behind these documents so you know it's important to mayor and council and the City therefore collaboration really isn't that hard when our elected officials deem these priorities. So it's important to them, therefore it's important to senior management team and that cascades down. That certainty or clarity helps" (P16).

Similarly, for elected officials, creating a broader vision document stitches together the various initiatives with regard to climate change and provides clarity and continuity of action across municipal departments. As one of the Mayors puts it: "We did our first ever environmental strategic plan under my leadership to ensure that we were addressing 
climate change issues, both as an organization as well as a community. That has resulted in quite a few changes: both internally about how we run our buildings and it also bled into our master transportation plan and other community policy documents. It's not that we weren't doing a lot of the work before, it just brought it into a strategic plan which is kind of the highest level document that we can create to guide the community and the organization" (P29).

A notable example of a broad vision document is Vancouver's Greenest City plan, created as a result of multi-year process that engaged 35,000 people, 120 organizations and over 65 staff across the municipality. All of the 5 Vancouver participants interviewed, from elected officials to engineering, emergency management and sustainability planners, noted that having an overarching strategic plan in place has significantly eased the adaptation process. This is because:

- Climate change was an accepted issue that the city decided to act on;

- Adaptation planning was a logical continuation of the mitigation work;

- The plan provided a framework for collaboration across various departments by aligning the aspirations and objectives around a common vision.

In addition to the broader sustainability plans that allow addressing climate change, Canadian communities [5] and BC communities in particular [42, 43], are well known internationally for their ability and preference to integrate climate planning as part of their daily operations and into exiting documents rather than standalone plans. One such opportunity is the process of revision of the Official Community Plans (OCP) which triggers searching for opportunities to combine mitigation, adaptation and broader long-term planning [41]. As a municipal official explained as part of the provincial review of adaptation policies: "It was also the adoption of our OCP that had specific language around climate change adaptation and mitigation contained within it that gave us, as staff, the freedom to move forward with starting a more formal process of developing an adaptation strategy" [41].

The provincial government in $\mathrm{BC}$ plays a limited role in incentivizing municipal hazard mitigation planning [44] but it provides guidelines through the Local Government Act, as outlined in the section above. Under this Act, municipalities can choose to adopt an OCP, a key document that guides development and planning and creates a long-term vision for community development. If the municipality chooses to adopt an OCP, then the Act requires inclusion of particular information, such as restriction of land use to hazardous or environmentally sensitive conditions. It is a well-known fact that an integrated, comprehensive long-term community plan can effectively mitigate natural hazards risk as part of land-use regulations and development restrictions (e.g. flood plain development) [14, 44, 45].

Many of the interviewees confirmed that official community plans serve as a way to introduce climate change language to long term planning, paving the way for municipality-wide action on mitigation and adaptation. The importance of ability to use the existing framework provided by the OCP as a foundation for municipal champions to build on and give adaptation approaches legitimacy was also highlighted in the provincial review [41]. While the OCP provides an opportunity to introduce climate change language, the plans lack the implementation capacity to address natural hazards risk at the local level. Therefore, they fail to reach the potential that locally-implemented, well-constructed land use plans have for reducing natural hazards risk.

Given the time variation within the region's OCP updates across the region (ranging from 1979 to 2014) it is clear that there is a lack of synchronization across the region in the treatment of climate change mitigation and adaptation. A detailed study of Metro Vancouver region's OCPs found that they lack not only consistency with regard to updates, but they also vary greatly in quality of factual base, generally lacking in hazard-related factual information, goals, policies, and mechanisms to promote plan 
implementation [44]. The study concludes that the plans in the region do not compare well to municipal hazard mitigation plans in the United States. OCPs thus fail to effectively address flood risk at the municipal level, let alone the regional level despite the potential that locally-implemented, well-constructed land use plans have for reducing natural hazards risk. Our findings indicated that without a more aggressive stance by the provincial government that is also backed by adequate resources, coordinated collaborative regional action is unlikely to grow soon. Our study, however, provides some basis for optimism based on the role that regional non-governmental organization and an international organization played in promoting regional coordination and collaboration.

\section{Bridging the municipal - provincial planning gap: the role of a mediating organization}

In the absence of aligned incentives across the multiple scales of governance an alternative mechanism for collaborative action has been identified through a mediating organization. The Fraser Basin Council (FBC) is a non-governmental regional organization that regularly brings stakeholders together for flood management purposes under the Joint Program Committee which is comprised of municipal, regional and provincial staff as well as private sector and critical infrastructure operators among others. The FBC is a unique not-for-profit organization, created in 1997 and dedicated to advancing social, economic, and environmental sustainability throughout the 240,000 square kilometres of the Fraser River Basin [46]. FBC facilitates collaborative action among various levels of government, the private sector, and civil society to solve complex, multi-jurisdictional issues in the Fraser Basin, to take advantage of opportunities, and to strengthen the capacity of institutions and individuals to deal with emerging issues that threaten the overall sustainability of the Basin. The first of its kind in Canada, it acts as a catalyst to minimize duplication and facilitate harmonization and collaboration across diverse interests [46].

FBC oversees the Joint Program Committee (JPC) for Integrated Flood Hazard Management, an ongoing regional forum for dialogue on flood management. It serves as a platform for regular meetings to share critical information, collaborate and build consensus, and develop management strategies that take into account a regional perspective and shared priorities that extend beyond the individual interests of its 34 municipal, provincial, federal and other members.

The regional survey among the municipalities revealed that, among the existing regional groups that facilitate flood management at the regional scale, the FBC was the leading organization that enabled collaboration and learning with regard to regional flood management. It received the highest scores for regular collaboration (62\%). Nearly $39 \%$ of respondents considered it influential and $46 \%$ suggested that they learn from the FBC.

FBC has no decision-making authority and relies on members to implement the consensus-based strategies and joint projects developed at the JPC. Although originally created to serve the needs of the river basin management, the organization has been responsive to the changing needs of its members and has fully embraced the new need to address coastal flooding. For this specific purpose, the organization raised USD 0.5 million from members and interested stakeholders to enable creation of a regional flood management strategy (with contributions starting from as low as USD 5,000 for some of its members). According to the FBC, this reflects "a serious, unprecedented commitment by the federal government, the Province of BC, 25 Lower Mainland local governments, and other public and private sector organizations to work together on flood protection measures that will safeguard the region as a whole" [47]. The strategy will be developed in several phases. The first phase focuses on developing a better understanding of flood hazards, identification of flood vulnerabilities, and assessment of flood management 
practices and policies from a regional perspective. Subsequently, from 2016 onward, FBC will seek to complete strategy development and will set out options for funding and implementation.

One important observation made by the participants is with regard to the stakeholder composition (i.e. who is invited to be part of these discussions). Historically, the JPC meetings were attended primarily by "higher folks" (P24) such as senior municipal engineers. However, increasingly some planners were invited in the conversation, which spoke to the broadening of flood management as part of the shared municipal responsibility.

Our findings show that in the absence of oversight, aligned incentives or dedicated resources for addressing climate change from the provincial government a patchwork of municipal responses is evolving in an uncoordinated way. This can result in maladaptation at the regional level both in the short term (e.g. different heights of dikes that increase flood risk downstream) and long-term (varied hazards and capacity of municipalities to address risk across the region). While some mechanisms have emerged in this non-amalgamated region to counteract some of this through mediating organizations, they lack authority and decision making power. The devolved responsibility for land use, development and risk management that falls on municipalities under the current regime aligns with the subsidiarity principle which speaks to making decisions at the most local level possible [27] by elected officials that are closest to the citizenry [24]. However, as the discussion above has shown, without the appropriate resources for climate change action what could be seen as local empowerment becomes direct downloading on already overstretched municipal budgets that have tocater to the immediate needs of their residents and electorate (for example, housing and policing rather than long-term adaptation).

Given the longitudinal nature of this study that tracked adaptation process over the period of 2.5 years our findings show that the overall governance system does exhibit some characteristics of adaptive governance in its ability to bring together "coordinated efforts involving previously independent systems of users, knowledge, authorities and organized interests" [21] as a mediating organization, the Fraser Basin Council, steps in with a mandate to generate long-term, sustainable policy solutions to 'wicked problems' [21]. However, these interests, while expanding in diversity, are currently still represented by the usual suspects such as various levels of government, powerful critical infrastructure operators and established professionals (primarily senior-level engineers). At the time of study there was little evidence of incorporation of other systems of knowledge (for example, traditional knowledge of First Nations people on whose territories this region is located) into the formal regional planning processes.

\section{CONCLUSIONS AND RECOMMENDATIONS}

Regional coordination and collaboration are essential to an effective response to climate change. Yet, as our study shows, herding cats in a non-amalgamated region is a formidable task. Recognizing climate change adaptation as municipal and regional issues requires attention, learning and legitimization by a broad range of stakeholders. The study reveals that the level of this attention, the implementation capacity and the willingness to self-regulate risk through existing mechanisms such as Official Community plans varies greatly across the region. The fragmentation of the governance system fails to account for interdependent cumulative effects of land-use changes and planning initiatives that spill over municipal boundaries. This, potentially, also may lead to missed opportunities with regard to exploiting procedural and substantive benefits of collaboration for the region as a whole as it moves on, developing the adaptation agenda.

Our study highlights the intergovernmental challenges of adaptation policies. We find that moves by the provincial government (including amendments to the land use and 
hazard management guidelines and the Cost of Adaptation Study) while drawing the attention of municipal officials and planners to the issue, have failed to trigger any significant action from most of the municipalities. Exceptions were the larger well-resourced municipalities which previously have made significant progress on their mitigation planning. The provincial government, while providing guidelines for action, left municipalities on their own to make sense of the looming threats of climate change (such as sea level rise) and articulate their response options. It appears that in the absence of an active participation of a higher level of government that employs its regulatory authority, provides effective incentives and ensures the ability of municipalities to access the necessary resources, coordinated collaborative actions driven by municipalities are unlikely to develop. A lack of a coordinated and systematic approach to the management of natural hazards risks at the regional level that is due to an inconsistent knowledge base and the absence of regional oversight of municipal actions, can result in a sub-optimal approach to public safety.

Our study also highlights the role that non-governmental networks can play in disseminating knowledge, encouraging learning and legitimizing and prioritizing climate change mitigation and adaptation. As the discussion has shown, the Fraser Basin Council, a unique non-governmental organization serves as one of the main regional platforms for information exchange, solutions sharing and collective sense-making. Learning leads to convergence in knowledge and perspectives, promoting communication and thus coordination and synergies as similar learned practices are adopted. However, the organization lacks regional implementation authority, relying on consensus driven policy creation and voluntary adoption of the policies and best practices. This voluntary mechanism, however, cannot fully address the fragmentation of implementation initiatives across the region. While coordination and collaboration in regional planning is theoretically achievable in this non-amalgamated region that celebrates diversity of its member municipalities without participation of the provincial government as an active partner, "implementation" will require its active role as a partner. Additionally, future studies will need to address the role of the federal government in the process of climate change adaptation given the scale and the magnitude of required regulation and financing that municipalities, regions and even provinces are unlikely to be able to meet on their own.

Finally, regional collaborative planning processes must engage and mobilize the public. The study showed that till now adaptation policies and planning have been seen primarily as an internal organizational and inter-organizational objective. This is in striking contrast to the development of climate change mitigation policies in the region. These were developed through a series of public consultations and engagement mechanisms (though their intensities varied greatly across the region). As municipalities come to realize the risks that they face, it would be important to engage in public consultation as part of design and evaluation of climate change adaptation options.

\section{REFERENCES}

1. Milly, P. C. D., Betancourt, J., Falkenmark, M., Hirsch, R. M., Kundzewicz, Z. W., Lettenmaier, D. P., et al., Stationarity is Dead: Whither Water Management?, Science, Vol. 319, No. 5863, pp 573-574, 2008, https://doi.org/10.1126/science.1151915

2. Buceti, G., Climate Change and Vulnerabilities of the European Energy Balance, Journal of Sustainable Development of Energy, Water and Environment Systems, Vol. 3, No. 1, pp 106-117, 2015, https://doi.org/10.13044/j.sdewes.2015.03.0008

3. Hulme, M., Jenkins, G. J., Brooks, N., Cresswell, D., Doherty, R. M., Durman, C., et al., What is happening to Global Climate and Why? Health Effects of Climate Change in the UK, London: Department of Health Report, UK, pp 18-49, 2002. 
4. Satterthwaite, D., Huq, S., Pelling, M., Reid, H. and Romero Lankao, P., Adapting to Climate Change in Urban Areas: The Possibilities and Constraints in Low- and Middle-income Nations (Bicknell, J., Dodman, D. and Satterthwaite, D., eds.), Adapting Cities to Climate Change, London: Earthscan, UK, 2009.

5. Aylett, A., Progress and Challenges in the Urban Governance of Climate Change: Results of a Global Survey, Cambridge, MA: MIT, USA, 2014.

6. Shakya, S. R., Benefits of Low Carbon Development Strategies in Emerging Cities of Developing Country: A Case of Kathmandu, Journal of Sustainable Development of Energy, Water, and Environment Systems, Vol. 4, No. 2, pp141-160, 2016, https://doi.org/10.13044/j.sdewes.2016.04.0012

7. Vogel, B. and Henstra, D., Studying Local Climate Adaptation: A Heuristic Research Framework for Comparative Policy Analysis, Global Environ. Change, Vol. 31, pp 110-120, 2015, https://doi.org/10.1016/j.gloenvcha.2015.01.001

8. Clean Energy Canada, How to adopt a Winning Carbon Price: Top Ten takeaways from Interviews with the Architects of British Columbia's Carbon Tax, Cleaner Energy Canada, pp 1-32, 2015.

9. Roberts, D., Thinking Globally, acting Locally - Institutionalizing Climate Change at the Local Government Level in Durban, South Africa, Environ. and Urban., Vol. 20, No. 2, pp 521-537, 2008, https://doi.org/10.1177/0956247808096126

10. Handmer, J. and Dovers, S., A Typology of Resilience: Rethinking Institutions for Sustainable Development, Organ. and Environ., Vol. 9, No. 4, pp 482-511, 1996, https://doi.org/10.1177/108602669600900403

11. Wagner, G. and Zechhauser, R., Climate Policy: Hard Problem, Soft Thinking, Climatic Change, Vol. 110, No. 3-4, pp 507-521, 2012, https://doi.org/10.1007/s10584-011-0067-z

12. May, P. J. and Williams, W., Disaster Policy Implementation: Managing Programs Under Shared Governance, New York: Plenum, USA, 1986, https://doi.org/10.1007/978-1-4613-2153-8

13. Berke, P., Lyles, W. and Smith, G., Impacts of Federal and State Hazard Mitigation Policies on Local Land Use Policy, J. Plan. Educ. Res., Vol. 34, pp 60-76, 2014, https://doi.org/10.1177/0739456X13517004

14. Mileti, D., Disasters by Design: A Reassessment of Natural Hazards in the United States, Washington D. C., Joseph Henry, USA, 1999.

15. Shi, L., Chu, E. and Debats, J., Explaining Progress in Climate Adaptation Planning Across 156 US Municipalities, Journal of American Planning Association, Vol. 81, No. 3, pp 191-202, 2015, https://doi.org/10.1080/01944363.2015.1074526

16. Juhola, S. and Westerhoff, L., Challenges of Adaptation to Climate Change across Multiple Scales: A Case Study of Network Governance in two European Countries, Environ. Sci. Policy, Vol. 14, No. 3, pp 239-247, 2011, https://doi.org/10.1016/j.envsci.2010.12.006

17. van Buuren, A., Driessen, P., Teisman, G. and van Rijswick, M., Toward Legitimate Governance Strategies for Climate Adaptation in the Netherlands: Combining Insights from a Legal, Planning, and Network Perspective, Regional Environmental Change, Vol. 14, No. 3, pp 1021-1033, 2014, https://doi.org/10.1007/s10113-013-0448-0

18. Minoia, P., Calzavara, A., Lovo, L. and Zanetto, G., An assessment of the Principle of Subsidiarity in Urban Planning to Face Climate Change, International Journal of Climate Change Strategies and Management, Vol. 1, No. 1, pp 63-74, 2009, https://doi.org/10.1108/17568690910934408

19. Vella, K., Butler, W. H., Sipe, N., Chapin, T. and Murley, J., Voluntary Collaboration for Adaptive Governance: The Southeast Florida Regional Climate Change Compact, Journal of Planning Education and Research, Vol. 36, No. 3, pp 363-376, 2016, https://doi.org/10.1177/0739456X16659700 
20. Phares, D., Governance or Government in Metro Areas - Introduction (Phares, D., ed.), Metropolitan Governance without Metropolitan Government? Burlington: Ashgate, USA, pp 1-6, 2004.

21. Scholz, J. T. and Stiftel, B. (eds.), Adaptive Governance and Water Conflict: New Institutions for Collaborative Planning, Washington: Resources for the FuturePress, USA, pp 1-13, 2005.

22. Stephens, G. R. and Wikstrom, N., Metropolitan Government and Governance, New York: Oxford University Press, USA, 2000.

23. Boothroyd, P., Metropolitan Governance: Responding to the Growing Challenge (Kellas, H. and Castro, E., eds.), Inclusion, Collaboration and Urban Governance: Brazilian and Canadian Experiences, Vancouver: The University of British Columbia; Rio de Janeiro: Observatório das Metrópoles; Belo Horizonte: Ed., PUC Minas, pp 429-440, 2010.

24. UN Habitat, World Cities Report, pp 1-26, 2016.

25. UNDP, Local Governance and Climate Change - A Discussion Note, 2010.

26. Minoia, P., Calzavara, A., Lovo, L. and Zanetto, G., An Assessment of the Principle of Subsidiarity in Urban Planning to Face Climate Change, International Journal of Climate Change Strategies and Management, Vol. 1, No. 1, pp 63-74, 2009, https://doi.org/10.1108/17568690910934408

27. Wilkins, R., Federalism and the Emergency Services: Paper developed from a Speech Presented at the AFAC/Bushfire CRC 2009 Conference, Australian Journal of Emergency Management, Vol. 25, No. 1, pp 3-6, 2010.

28. West Coast Environmental Law and Modus Planning, Green Waterfront Design Charrette Brief, Vancouver, Canada, 2014.

29. Park Associates, The Economic Importance of the Lower Fraser River, Vancouver, Canada, 2014.

30. Flood and the Fraser, Vancouver: The Fraser Basin Council, c1997-2015, http://www.fraserbasin.bc.ca/water_flood_fraser.html, [Accessed: 14-March-2014]

31. Heaslip, E., Costello, G. J. and Lohan, J., Assessing Good-practice Frameworks for the Development of Sustainable Energy Communities in Europe: Lessons from Denmark and Ireland, Journal of Sustainable Development of Energy, Water, and Environmental Systems, Vol. 4, No. 3, pp 307-319, 2016, https://doi.org/10.13044/j.sdewes.2016.04.0024

32. Yumagulova, L., Resilient by Design: The Role of Institutional Adaptation to Environmental Risk in Cities (Dissertation), Vancouver (BC), University of British Columbia, Canada, Forthcoming.

33. Harcourt, M., Cameron, K. and Rossiter, S., City making in Paradise: Nine Decisions that saved Vancouver, Vancouver: Douglas and McIntryre, Canada, 2007.

34. Slaymaker, O., Natural Hazards in British Columbia: An Interdisciplinary and Interinstitutional Challenge, Int. J. Earth Sci., Vol. 88, No. 2, pp 317-324, 1999, https://doi.org/10.1007/s005310050267

35. Bornhold, B., Projected Sea Level Changes for British Columbia in the $21^{\text {st }}$ Century, BC: Province of British Columbia and Government of Canada, Canada, 2008.

36. Ausenco Sandwell, Climate Change Adaptation Guidelines for Sea Dikes and Coastal Flood Hazard Land Use, Draft Policy Discussion Paper, Vancouver, Canada, 2011.

37. Professional Engineers and Geoscientists of B. C. Ministry of Forests, Lands and Natural Resource Operations, Natural Resources Canada. Professional Practice Guidelines-Legislated Flood Assessments in a Changing Climate in BC, Vancouver, Canada, 2012.

38. Kerr Wood Leidal Associates Ltd., Coastal Floodplain Mapping - Guidelines and Specifications, Final Report for Ministry of Forests, Lands and Natural Resource Operations (MFLNRO), Victoria, Canada, MFLNRO, 2011, 
http://www.env.gov.bc.ca/wsd/public_safety/flood/fhm-2012/draw_report.html\#3, [Accessed: 14-March-2014]

39. Arlington Group, Sea Level Rise adaptation Primer, Prepared for B. C. Ministry of Environment, 152 p, 2013.

40. Proposed Amendments to BC Flood Hazard Area Land use, Victoria, Canada, Capital Regional District, https://www.crd.bc.ca/docs/default-source/news-pdf/proposedamendmentstobcfloodha zardarealanduse.pdf?sfvrsn=0, [Accessed: 12-March-2015]

41. Sustainability Solutions Group (MC3), Adaptation Planning: The Local Government Experience in B. C., B. C. Ministry of Environment, pp 1-9, 2013.

42. Picketts, I. M. and Curry, J., Planning for Climate change Adaptation in British Columbia Communities: Lessons for Planners, Int. J. Sus. Soc., Vol. 3, No. 4, pp 397-413, 2011, https://doi.org/10.1504/IJSSOC.2011.043639

43. Picketts, I., Dery, S. and Curry, J., Incorporating Climate change Adaptation into Local Plans, J. Environ. Plann. Mann., Vol. 57, No. 7, pp 984-1002, 2014, https://doi.org/10.1080/09640568.2013.776951

44. Stevens, M. and Shoubridge, J., Municipal Hazard Mitigation Planning: A Comparison of Plans in British Columbia and the United States, J. Environ. Plann. Mann., Vol. 58, No. 11, pp 1-27, 2015, https://doi.org/10.1080/09640568.2014.973479

45. Burby, R. (ed.), Cooperating with Nature: Confronting Natural Hazards with Land-use Planning for Sustainable Communities, Washington D. C., John Henry Press, USA, 1998.

46. Marshall, D., Collaborative Metropolitan Governance for Social Inclusion (Kellas, H. and Castro, E., eds.), Inclusion, Collaboration and Urban Governance: Brazilian and Canadian Experiences, Vancouver: The University of British Columbia, Rio de Janeiro: Observatório das Metrópoles, Belo Horizonte, ed, PUC Minas, pp 251-260, 2012.

47. Canadian Consulting Engineer, News Blog, Toronto: Canadian Consulting Engineer, Lower Mainland of B. C. to boost Flood Prevention, http://www.canadianconsultingengineer.com/environmental/lower-mainland-of-b-c-toboost-flood-prevention/1003178545/, [Accessed: 01-July-2015] 